\title{
Geomorfologia da Serra do Feiticeiro em Lajes/RN
}

\author{
Geomorphology of the Serra do Feiticeiro in Lajes / RN \\ BEZERRA $^{1}$,G. R. F.; ARAÚJO2 ${ }^{2}$ J. B. P.; SARAIVA JUNIOR ${ }^{3}$,J. C. \\ grfbezerra@gmail.com;
}

\begin{abstract}
Resumo
Os compartimentos geomorfológicos da Superfície Sertaneja do Rio Grande do Norte são o resultado da conjugação de diversos processos que remontam a fusão e divisão de paleocontinentes, deformações estruturais e processos de pediplanação marcadamente a partir do Paleógeno. No município de Lajes/RN, relevos de modesta altitude interrompem a planura suave da Superfície Sertaneja, constituindo-se em elementos importantes para a compreensão da evolução geomorfológica potiguar, destacando entre eles o Pico do Cabugi, como registro do mais jovem evento magmático na porção continental do Brasil e a Serra do Feiticeiro. Assim, o objetivo geral deste trabalho é discutir a geomorfologia da Serra do Feiticeiro e sua importância na dinâmica ambiental de Lajes. A metodologia é baseada em revisão da literatura científica, trabalhos de campo e aplicação de geoprocessamento. Os resultados apontam que a Serra do Feiticeiro é um maciço estrutural originado pela fissão e junção de paleocontinentes. A evolução ulterior sugere que suas escarpas foram fortemente afetadas por falhamentos e erosão diferencial. A hidrografia de Lajes é fortemente influenciada pela existência desse relevo que é um importante divisor de bacias hidrográficas.
\end{abstract}

Palavras-chave: Morfoestruturas, Serra do Feiticeiro, Lajes/RN.

\begin{abstract}
Geomorphological compartments of Surface Sertaneja of Rio Grande do Norte are the combined result of various processes that go back paleocontinentes merger and division, structural deformations and pediplanation processes markedly from the Paleogene. In the municipality of Lajes / RN, modest altitude reliefs interrupt the smooth flatness of the Surface Sertaneja, constituting an important element for understanding the Potiguar geomorphological evolution, highlighting among them the Pico do Cabugi, as a record of the younger magmatic event in the portion continental the Brazil and Serra do Feiticeiro. Thus, the aim of this study is to discuss the geomorphology of the Serra do Feiticeiro and its importance in environmental dynamics of Lajes. The methodology is based on review of scientific literature, field work and application of GIS. The results show that the Serra do Feiticeiro is a structural mass caused by the fission and paleocontinentes junction. Subsequent developments suggest that their escarpments were strongly affected by faulting and differential erosion. The Lajes hydrography is strongly influenced by the existence of this relief is an important divider watershed.
\end{abstract}

Keywords: Morphostructure, Serra do Feiticeiro, Lajes/RN.

\section{INTRODUÇÃO}

O relevo do semiárido Nordestino é resultado de sucessivas fases de estruturação geológica que incluíram colagem e fissão de continentes e alternância das fases de mudanças climáticas que implicaram em variações morfológicas, em função dos diferentes graus de resistência dos grupos litológicos que sustentam as vertentes.

Alguns estados nordestinos possuem modelados sustentados ora por rochas cristalinas ora por depósitos sedimentares. No Rio Grande do Norte, as unidades geomorfológicas definidas na

${ }^{l}$ Gleydson Rubens de Farias Bezerra, Diretoria Acadêmica de Recursos Naturais, Instituto Federal do Rio Grande do Norte; Departamento de Geologia, Universidade Federal do Rio Grande do Norte, Natal-RN, Brasil.

${ }^{2}$ Joanderson Batista Pereira Araújo, Diretoria Acadêmica de Recursos Naturais, Instituto Federal do Rio Grande do Norte; Departamento de Geologia, Universidade Federal do Rio Grande do Norte, Natal-RN, Brasil. ${ }_{3}^{3}$ João Correia Saraiva Junior, Diretoria Acadêmica de Ciências, Instituto Federal do Rio Grande do Norte, Natal-RN, Brasil. 
escala de 1:250.000, encontram-se distribuídas basicamente em Planície Costeira, Tabuleiros Litorâneos, Chapadas, Depressão Sertaneja e Maciços Estruturais (CPRM, 2010; MAIA,2013).

O município de Lajes está localizado na Depressão Sertaneja Potiguar apresentando variações altimétricas definidas em função de litologias, processos externos influenciados fortemente pelas variações térmicas e deformações estruturais. Os compartimentos do relevo de Lajes foram indicados por Ferreira e Sial (1999) e Szilagyi (2007) com destaque para a Serra do Feiticeiro, Depressão Sertaneja e o neck do Cabugi. No entanto, a descrição geomorfológica da Serra do Feiticeiro não foi discutida.

Nesse sentido, o objetivo geral deste artigo é analisar a Geomorfologia da Serra do Feiticeiro no município de Lajes/RN (Figura 01). Os objetivos específicos buscaram realizar a caracterização dos componentes geoambientais do setor de estudo que influenciam e são influenciados pelo relevo. Na sequência, buscou-se compreender a estruturação geológica do setor de estudo que apresenta forte influência na organização geomorfológica e, ainda, a descrição dos compartimentos geomorfológicos.

Inicialmente são apresentados os percursos metodológicos necessários para o desenvolvimento da pesquisa. Na sequência é realizada a contextualização da Serra do Feiticeiro no ambiente do município de Lajes, seguido da discussão sobre a origem dos diferentes grupos litológicos, influência dos paleoclimas e descrição da compartimentação do relevo.

\section{METODOLOGIA}

Para a realização do trabalho foram realizadas consultas referentes à área em estudo e adjacente, levantamento de dados em livros, artigos, teses e dissertações e em material cartográfico a fim de se obter o maior conhecimento possível sobre as características geológicas.

Além das consultas bibliográficas, foi realizado trabalho de campo para verificação da verdade terrestre. Nessa etapa foram utilizados o receptor do GPS, mapas temáticos e equipamentos para registros fotográficos.

A confecção dos mapas foi elaborada na terceira etapa da pesquisa, com o objetivo de evidenciar e apresentar cartograficamente os resultados do trabalho, superpondo dados geológicos a dados topográficos.

Para a confecção dos mapas apresentados, os programas Google Earth Pro, versão 7.1.5.1557, da empresa Google Inc., e ArcGis, mais especificamente o ArcMap, versão 10.3, da empresa Esri foram utilizados. Serviram como base para a confecção, imagens georreferenciadas, retiradas do primeiro programa citado, assim como do website Earth Explore, pertencente à USGS 
(United States Geological Survey). Para a edição dos mapas foram criados e editados shapes de temas como dados geológicos, topográficos e de drenagem superficial.

A Serra do Feiticeiro dista cerca de $150 \mathrm{~km}$ da capital Natal. O acesso ao local de estudo ocorre pela BR-304 sentido E-W saindo de Natal para Mossoró e estradas carroçais no sentido S.

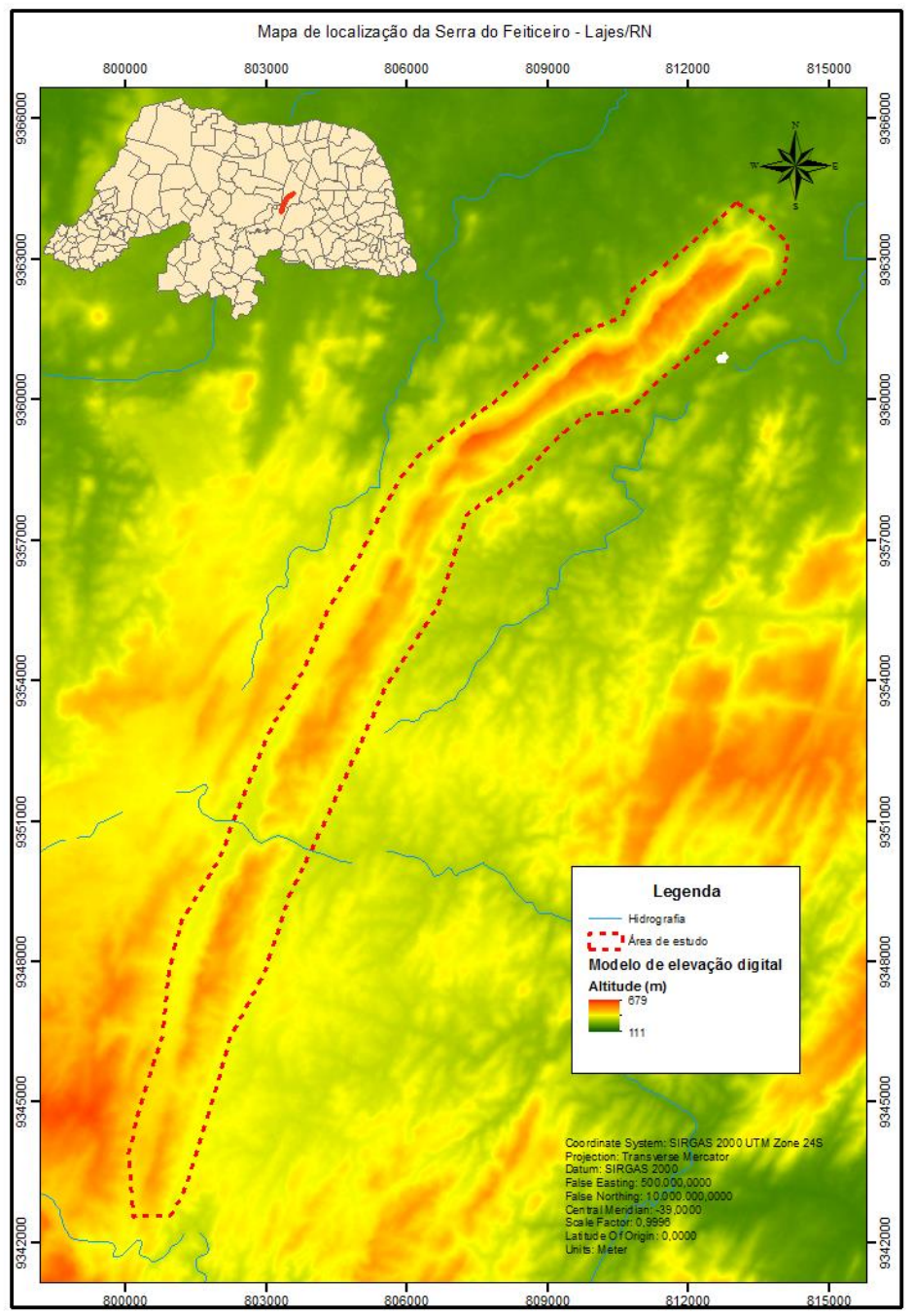

Figura 01. Mapa de localização da Serra do Feiticeiro. Fonte: Joanderson B. P. Araújo (2015).

O uso e ocupação do relevo da Serra do Feiticeiro é marcado pela agricultura e criação de gado. Distritos de recursos minerais são apontados pelo Departamento Nacional de Produção Mineral. Inclusive alguns foram abandonados no contato entre as vertentes da Serra do Feiticeiro e Depressão Sertaneja.

\section{RESULTADOS E DISCUSSÃO}

A dinâmica ambiental de Lajes é marcada pela influência de um clima muito quente e semiárido, com, segundo Nimer (1979), estação chuvosa atrasada para o outono e com períodos secos da ordem de 8 meses. Segundo dados fornecidos pelo Governo do Estado do Rio Grande do 
Norte em 2003, a umidade anual média relativa da Região é de 70\%, insolação de 2400 Hora/ano, temperatura média de $27,2^{\circ} \mathrm{C}$, com máximas anuais acima de $33^{\circ} \mathrm{C}$.

Quanto à hidrografia, a principal característica da região da área de estudo é pertencer, 90\% do território, à bacia hidrográfica do Rio Ceará-Mirim, apresentando, como principais tributários que drenam Lajes, os rios Boa Vista, Quintimproá e Novo, além dos Riachos Cachoeirinha, Salgado, Meio, Trapiá, Picos, Pretos, Queiroz, Urubu, Porcos, Juazeiro, Amarante, Arizona, Maniçoba e Bonfim, sendo, este último, o que corta a área de estudo.

A associação dos elementos clima, geologia, hidrografia e geomorfologia de Lajes resultaram na formação de três tipos de solos distintos (Luvissolos, Cambissolos e Neossolos) (EMBRAPA,1999). No entorno da área de estudo, onde se encontra um predomínio de rochas cristalinas, estão presentes os Luvissolos que apresentam profundidades variáveis entre 10 à $50 \mathrm{~cm}$. Com grande presença de argila com coloração avermelhada a bruno-avermelhada, pode ser caracterizado o horizonte $\mathrm{B}$ textural $(\mathrm{Bt})$. Apresentando baixos teores de matéria orgânica, esses solos possuem alta fertilidade natural. $\mathrm{O}$ pH destes solos (entre 6,0 e 7,0) e por serem solos rasos e pedregosos fazem com que seja restrito para culturas de ciclo curto, como o algodão. Por possuírem alta suscetibilidade a erosão e salinização, são considerados solos de elevada fragilidade ambiental, o que ocasiona a necessidade de planos de manejo para sua utilização (SZILAGYI,2007).

A formação vegetal da área de estudo é do tipo Caatinga Hiperxerófila, que pode ser caracterizada como uma vegetação de caráter mais seco, com grande presença cactácea e plantas de porte mais baixo e espalhadas. Apresentando predominância de plantas de porte herbáceo e arbustivo e com maioria dos espécimes descopadas devido ao período de seca, resultante de adaptação da flora desse tipo de Caatinga, que acaba evitando a perca de água através da transpiração que ocorreria através dos estômatos presentes nas folhas. As peculiaridades do ecossistema Caatinga, são decorrentes de condições climáticas extremas do local de seu desenvolvimento. Tais condições são, por exemplo, precipitações baixas e irregulares, além exposição a alta radiação solar, altas temperaturas médias anuais, baixa nebulosidade, taxas de umidade relativa baixas e evapotranspiração potencial elevada (LEAL et al, Op. cit).

O relevo influencia fortemente as características ambientais de Lajes sendo, também, influenciado pelos demais elementos da paisagem. A compreensão da origem do relevo e sua atual configuração constitui-se em importante ferramenta da gestão ambiental dos espaços do semiárido.

\subsection{Elementos da estruturação geológica}

A evolução geológica do embasamento cristalino potiguar se dá a partir de acreção de arcos magmáticos com contribuição de material juvenil ainda no Paleoproterozóico. Essas sucessivas 
acresções magmáticas resultaram na formação do Domínio São José do Campestre e Domínio Rio Piranhas-Seridó. Durante o Paleoproterozóico ocorre a primeira fusão (colagem do supercontinente Atlântida) que reflete em grande parte como: i) ambientes intracratônicos/intraplacas (associado e confirmado com magmatismo máfico-ultramáfico, sinéclises e assemelhados, riftes, etc.); e ii) ambientes de interação de placas continentais (colisão e transpressão) e oceânicas (magmatismo arc-related). O surgimento do protocontinente $(2,3$ a 2,15 Ga) é devido a sucessivas amalgamações de arcos magmáticos de tipo back-arc - característico do ambiente oceânico - com magmatismo dominantemente do tipo juvenil, extraído de um manto metassomatizado, referente ao G1 (JARDIM DE SÁ, 1990). Esta protocrosta é denominada de Complexo Caicó (embasamento do Rio PiranhasSeridó).

No encerramento do Paleoproterozóico $(2,0 \mathrm{Ga})$ é traduzida uma atividade granítica sin a tarditectônica que relata uma possível documentação da colagem do cinturão transamazônico dos Domínios Jaguaribeano, Rio Piranhas-Seridó e São José do Campestre Durante o evento Rodínia. Ao iniciar o Neoproterozóico ocorre um processo de extensão onde inicia-se a extrusão de pulsos magmáticos entre 900 e 750 Ma. A extrusão desse material mantélico implica na deposição do Grupo Seridó sotoposto ao embasamento, constituindo a Faixa Seridó (ANGELIM et al., 2006).

O terceiro evento orogênico é a colagem Brasiliano/Pan Africana em 600 Ma que resulta da convergência entre os crátons São Francisco e Oeste da África (BRITO NEVES,1999). Ela é registrada, em nosso embasamento, por dois eventos: um deformacional (D1/D2) com empurrões para WNW; e um tectônico transcorrente (D3) associado a expressivas zonas de cisalhamento dominantemente dextrais/transpressionais com direção preferencial NE-SW (ANGELIM et al., 2006).

As tipologias litológicas da Serra do Feiticeiro e embasamento adjacente (Figura 02) podem ser resumidas em Quartzitos da Formação Equador (cinza), Gnaisses e Granitos do Complexo Caicó (rosa claro), Gnaisses da Formação Jucurutu (bege claro), Micaxistos da Formação Seridó (marrom) e depósitos aluvionares em menor expressão. 


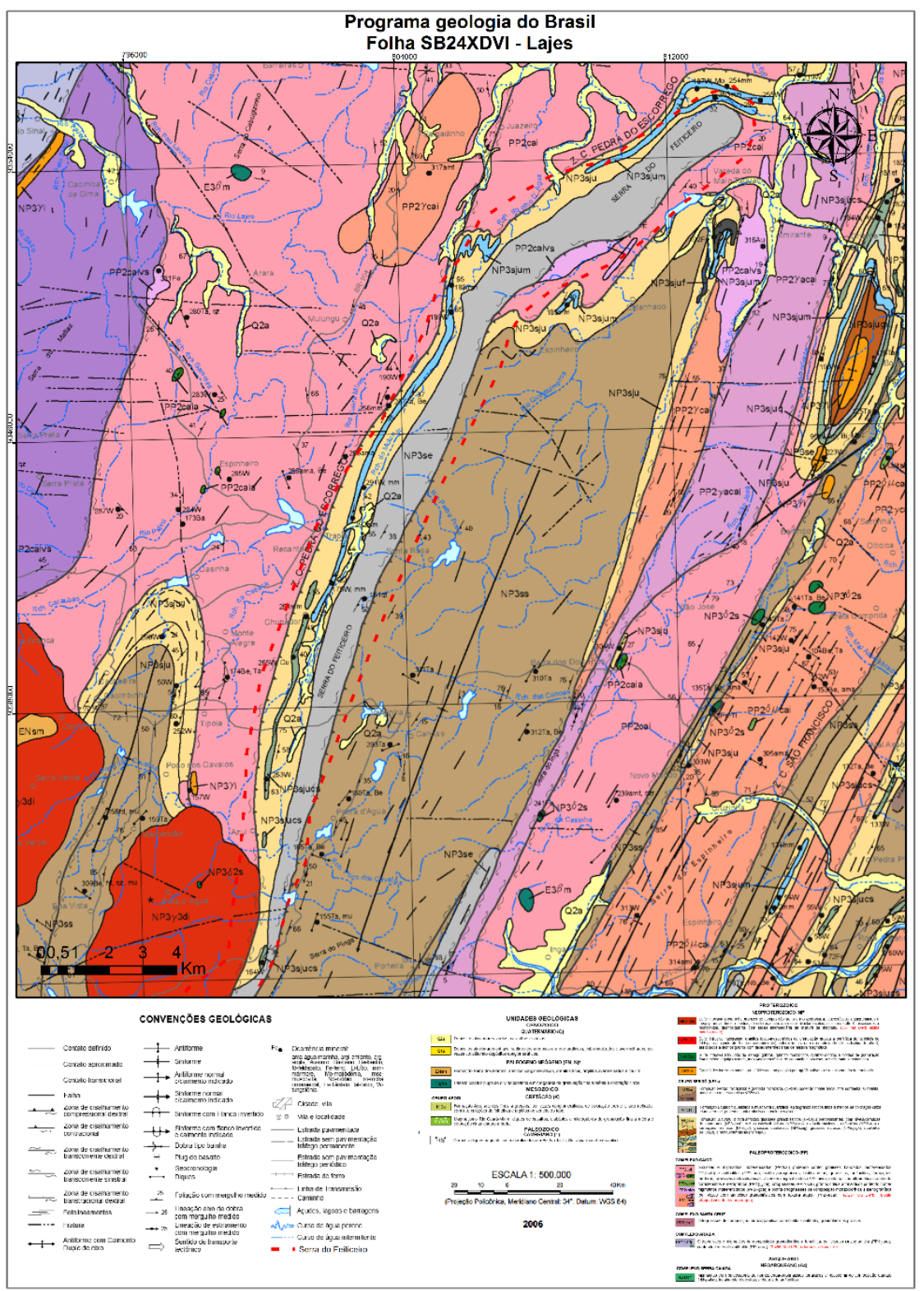

Figura 02. Esboço geológico evidenciando a Serra do Feiticeiro (adaptado). Fonte: CPRM (2014).

\subsection{Compartimentação geomorfológica}

O setor de estudo está situado entre O Planalto da Borborema e a Depressão Sertaneja, ambas unidades geomorfológicas. Na região existe, além da divisão desses compartimentos, uma intensa trama estrutural que resultou em uma evolução diferencial do relevo.

O Planalto da Borborema, principal domínio morfoestrutural do Nordeste, que constitui a região de arqueamento máximo do escudo nordestino, trata-se de um relevo de degradação em um maciço cristalino Pré-Cambriano, de direção geral NNE-SSW, com vastas superfícies planálticas alçadas em cotas que variam entre 450 e 1.000 metros de altitude, destacando-se nitidamente em relação às áreas circundantes (PFALTZGRAFF, 2010). 
No estado do Rio Grande do Norte, o Planalto da Borborema consiste de parte do seu rebordo norte, com amplitude de relevo variando de 300 a 700 metros, compreendendo um padrão de relevo composto de morros e serras de cotas mais baixas, pequenas cristas e esparsas superfícies planálticas com platôs recobertos por coberturas cenozoicas, delimitados por curtos rebordos erosivos e escarpas serranas, com alguns segmentos de relevo montanhoso destacados, representando relevos residuais remanescentes do grande planalto (PFALTZGRAFF, 2010).

A Depressão Sertaneja apresenta-se como uma depressão periférica em relação aos Baixos Platôs da Bacia Potiguar, em cotas baixas, entre 60 e 300 metros, e compreende padrões de relevo com amplo predomínio de superfícies aplainadas e suavemente onduladas, resultantes de processos de arrasamento generalizado do relevo sobre diversos tipos de litologias (PFALTZGRAFF, 2010).

Essas vastas superfícies encontram-se pontilhadas por inselbergs e maciços montanhosos isolados. Esse domínio é o mais extenso do território do Rio Grande do Norte e é formado por rochas do embasamento ígneo-metamórfico pré-cambriano da Faixa de Dobramentos do Nordeste, constituído por grande diversidade de litologias englobadas em quatro grandes domínios tectonoestruturais: Domínio São José do Campestre, do Núcleo Arqueano e de complexos paleoproterozoicos; Domínio Rio Piranhas-Seridó, Domínio das rochas granitoides associadas ao magmatismo brasiliano e Domínio Jaguaribeano (PFALTZGRAFF, 2010).

A Serra do Feiticeiro (Figura 03), é a segunda maior elevação da região da área de estudo, constituindo uma escarpa quartizítica resultante de uma zona de cisalhamento contracional de idade Proterozóica, possui aproximadamente $600 \mathrm{~m}$ de altitude e uma extensão de $25 \mathrm{~km}$, com orientação NE-SW. (SZILAGYI, 2007).

Possui uma altitude menor que o Pico do Cabugi, com qual a paisagem do município onde o setor de estudo se localiza mantém uma relação direta, por serem importantes divisores de água. O pico, por sua vez, constitui, a partir do Magmatismo Macau (Tm), de idade terciária eocênica (KAr), um Neck vulcânico, evidenciado por olivina-basaltos de filiação alcalina. (BRASIL, 1998; NESI, CARVALHO, 1999, p.32).

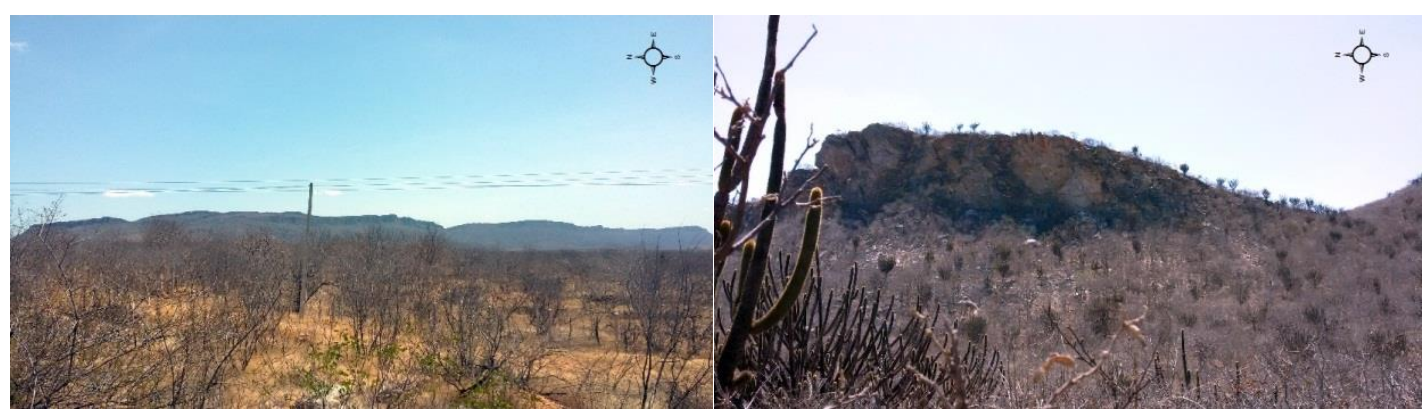

Figura 03 (esquerda) e 04 (direita). Serra do Feiticeiro. Fonte: Joanderson B. P. Araújo (2015) 
A compartimentação do relevo da Serra do Feiticeiro revela a existência de cristas residuais alinhadas, obedecendo a direção preferencial das falhas. Cristas residuais são definidas como relevos pontiagudos sustentados por litologias mais resistentes aos processos de erosão diferencial (Figura 04).

Os setores mais elevados são modelados em quartzitos, possuem cotas topográficas acima de $400 \mathrm{~m}$ de altitude, chegando a mais de $600 \mathrm{~m}$ no setor sul. Essas rochas metamórficas são bastante resistentes ao intemperismo e apresentam elevado grau de dureza (7) na escala de Mohs. Em função da predominância de quartzo na composição da Formação Equador, a permanência das cristas na paisagem pode ser resultado de menor suscetibilidade de decomposição na presença dos agentes externos.

Os falhamentos mapeados indicam o soerguimento da Formação Equador. O metamorfismo ocorre em ambiente de alta pressão e temperatura. Os eventos que deram origem aos falhamentos que são datados no contexto da colagem brasiliana, sendo reativadas no Cenozóico, como indicam os trabalhos de Maia, Bezerra e Claudino Sales (2008).

Ocupando as cotas topográficas situadas entre 200 e 400m de altitude está a Depressão Sertaneja (Superfície Sertaneja). A topografia esbatida é resultado do arrasamento das formações Jucurutu e Seridó. De acordo com o mapeamento geológico do setor de estudo (Figura 02), muitas fraturas foram identificadas em tais formações, potencializando a atuação dos processos de meteorização. Os processos mecânicos predominam praticamente o ano inteiro. A termoclastia e acebolamento facilitam a ação dos processos químicos evidentes durante a quadra chuvosa.

O intemperismo biológico, ainda que em baixa intensidade, em função da baixa disponibilidade hídrica, altera superficialmente a resistência das rochas, contribuindo nos processos de denudação dos pedimentos. Os Neossolos evidenciam a pedogênese incipiente e pouca alteração do manto intempérico.

Esse segmento corresponde a uma área de depressão relativa, cujo declínio é orientado para o litoral. As drenagens das microbacias modelaram planícies que acompanham pontos de fraqueza das rochas. Pequenas planícies aluviais são instaladas nesse processo. Os sedimentos clásticos predominam ao longo das calhas fluviais e em menor expressão estão presentes os depósitos aluvionares (areias e argilas) em área de convergência de fluxos. 


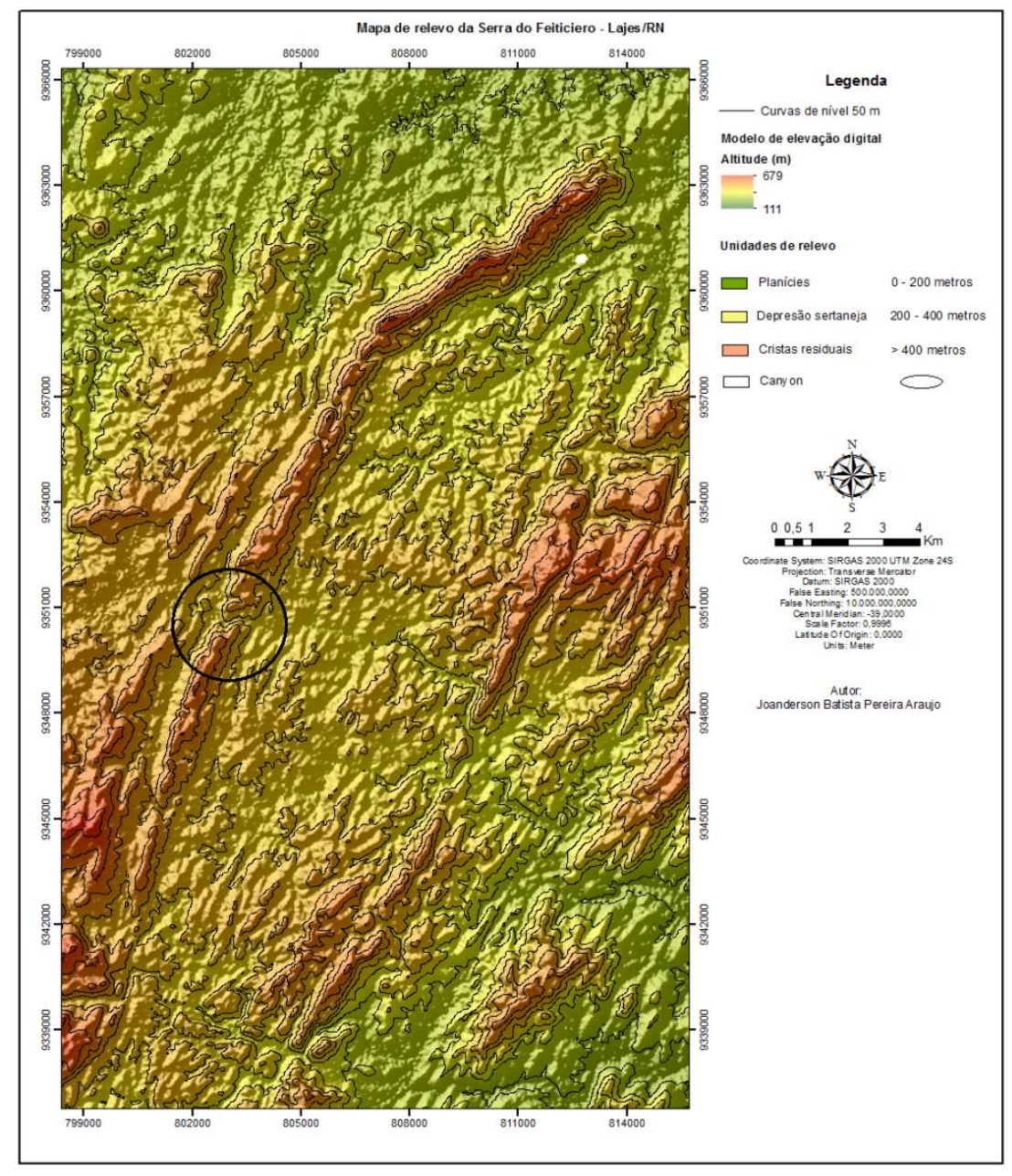

Figura 04. Mapa de relevo da Serra do Feiticeiro. Fonte: Joanderson B. P. Araújo (2016).

As vertentes da Serra do Feiticeiro são levemente orientadas para E. O escamento superficial concentrado em sulcos aprofundou setores de fragilidade das rochas e modelou um canyon de orientação W-E. Embora de expressão espacial reduzida, esse canyon representa uma etapa evolutiva que implica em captura fluvial ou superimposição de drenagens. Um pequeno curso cataclinal entalhou um talvegue capaz de segmentar em dois setores a Serra do Feiticeiro. O paralelismo das cristas denuncia que o relevo possui forte controle estrutural.

A compartimentação geomorfológica da Serra do Feiticeiro coloca em pauta diversas questões sobre a evolução geomorfológica de Lajes e efeitos da neotectônica nessa parcela da Depressão Sertaneja. 


\section{CONSIDERAÇÕES FINAIS}

As características ambientais de Lajes são marcadas pela semiaridez que provoca elevado déficit hídrico, predominância da Caatinga, Neossolos e relevos marcados por morfoestruturas.

A Serra do Feiticeiro, importante elevação do município de Lajes, apresenta morfologias que evidenciam a complexa evolução do relevo em ambiente de semiárido. Litologias formadas no contexto da fusão e fissão das placas e soerguimentos posteriores, associados às mudanças climáticas cenozóicas sugerem que outras pesquisas sejam realizadas sobre a gênese do relevo.

As morfologias presentes na área podem ser divididas em Cristas Residuais, Depressão Sertaneja, Canyon e Planícies Fluviais. Tais compartimentos são importantes divisores de microbacias hidrográficas.

\section{REFERÊNCIAS}

ANGELIM, L.A.A. et al. Ministério de Minas e Energia (Org.). GEOLOGIA E RECURSOS MINERAIS DO RIO GRANDE DO NORTE. Recife: CPRM, 2006. 119 p.

BRITO NEVES, B.B. América do Sul: quatro fusões, quatro fissões e o processo acrescionário andino. Revista Brasileira de Geociências, v. 29, n. 3, p. 379-392, 1999

EMBRAPA, CENTRO NACIONAL DE PESQUISA DE SOLOS. Sistema brasileiro de classificação de solos. Brasília/Rio de Janeiro: Embrapa, Serviço de Produção de Informação/Embrapa Solos. 1999. 412 p.

FERREIRA, V.P., SIAL, A.N. Pico do Cabugi, RN. Registro do mais jovem magmatismo continental do Brasil. SIGEP-Sítios Geológicos e Paleobiológicos, v. 39, p. 393-398, 1999.

LEAL, Inara R. et al. Ecologia e conservação da caatinga. Recife: Ed. Universitária da UFPE, 2003.

MAIA,R.P.; BEZERRA,F.H.;CLAUDINO SALES,V.C. Vales fluviais do Nordeste: considerações geomorfológicas. Revista Okara: Geografia em debate. Edição Especial - II Simpósio de Geografia Física do Nordeste. Vol. 2, N. 2 (2008).

NESI, Júlio Resende; CARVALHO, Valdecílio Galvão Duarte de. Minerais Industriais do Estado do Rio Grande do Norte. Recife: CPRM, 1999. 156p.

PFALTZGRAFF, P. A. S.; TORRES, F. S. M. Geodiversidade do estado do Rio Grande do Norte. Recife: CPRM, 2010.

SZILAGYI, Gustavo. Diagnóstico Ambiental do Processo de Desertificação no município de Lajes/RN. 114 f. Dissertação. UFRN - Programa de Pós-Graduação e Pesquisa em Geografia, Natal, 2007. Orientador Prof. Dr. Fernando Moreira da Silva. 


\section{AGRADECIMENTOS}

Ao IFRN pelo espaço físico para realização das reuniões e finalização deste trabalho.

Recebido em: 14/08/2016

Aceito para publicação em: 01/10/2016 